$$
\text { CONF- } 960859--6
$$

UCRL-JC-123646

PREPRINT

\title{
The Contribution of Carbonaceous Aerosols to Climate Change
}

\author{
J.E. Penner \\ C.C. Chuang \\ C. Liousse
}

RECEIVED

SEP 251996

OSTI

This paper was prepared for submittal to the

14th International Conference on Nucleation and Atmospheric Aerosols

Helsinki, Finland

August 26-30, 1996

April 1996

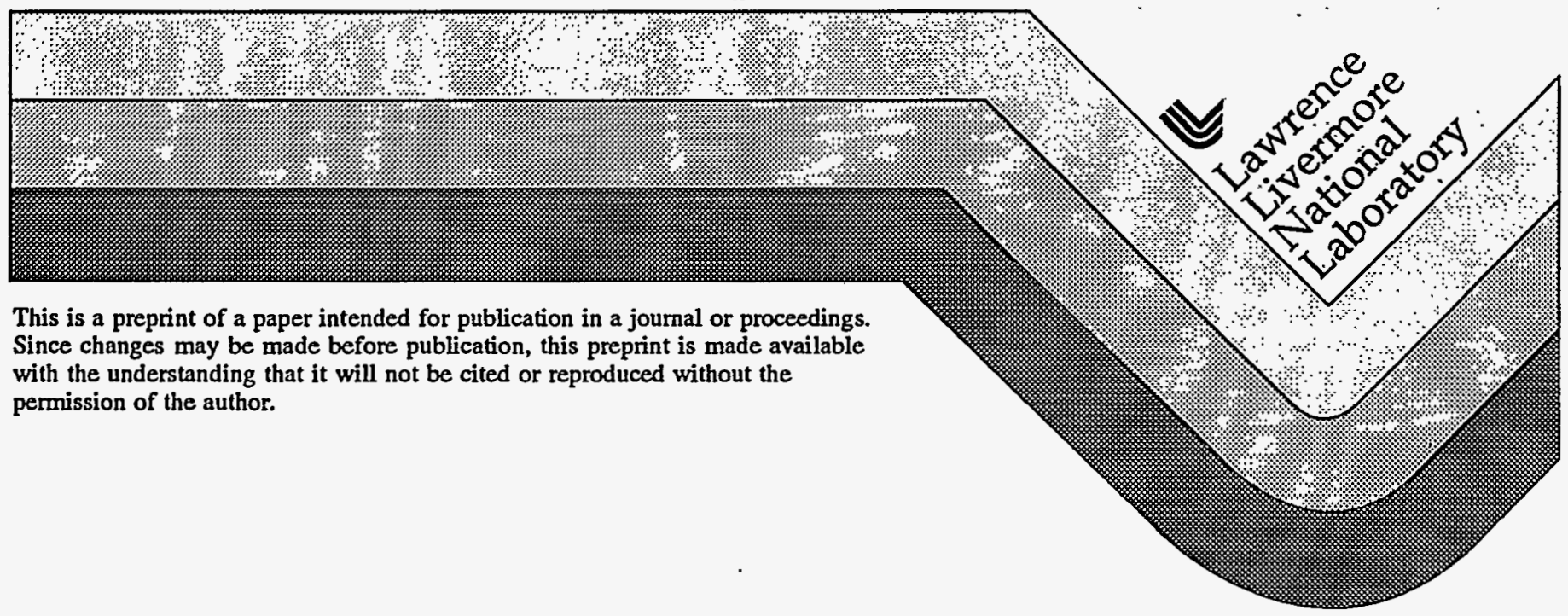
with the understanding that it will not be cited or reproduced without the permission of the author. 


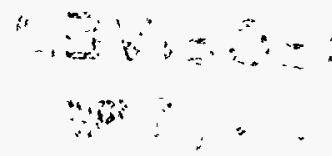

\section{DISCLAIMER}

This document was prepared as an account of work sponsored by an agency of the United States Government. Neither the United States Government nor the University of California nor any of their employees, makes any warranty, express or implied, or assumes any legal liability or responsibility for the accuracy, completeness, or usefulness of any information, apparatus, product, or process disclosed, or represents that its use would not infringe privately owned rights. Reference herein to any specific commercial product, process, or service by trade name, trademark, manufacturer, or otherwise, does not necessarily constitute or imply its endorsement, recommendation, or favoring by the United States Government or the University of California. The views and opinions of authors expressed herein do not necessarily state or reflect those of the United States Government or the University of California, and shall not be used for advertising or product endorsement purposes. 


\section{DISCLAIMER}

Portions of this document may be illegible in electronic image products. Images are produced from the best available original document. 


\title{
THE CONTRIBUTION OF CARBONACEOUS AEROSOLS TO CLIMATE CHANGE
}

\author{
Joyce E. Penner ${ }^{1,2}$, Catherine C. Chuang ${ }^{1}$, and Catherine Liousse ${ }^{3}$ \\ ${ }^{1}$ Atmospheric Science Division, Lawrence Livermore National Laboratory, Livermore, CA \\ 2Department of Atmospheric, Oceanic, and Space Sciences, University of Michigan, Ann Arbor, MI \\ ${ }^{3}$ Centre des Faibles Radioactivités, CNRS-CEA, ave de la terrasse, 91198 Gif sur Yvette, France
}

\begin{abstract}
The contribution of aerosols to climate change results from two effects: clearsky and cloudy-sky forcing. The clear-sky climate forcing by carbonaceous aerosols from biomass burning and fossil fuel burning depends on the relative contribution of scattering and absorption by the aerosols which in turn depends on the fraction of aerosol mass associated with black carbon and its size distribution. In this paper, we review estimates for the emission of carbonaceous aerosols, placing these estimates in the context of estimates for the emissions of anthropogenic and natural sulfate aerosols and natural sources of organic particulate matter.

The cloudy-sky forcing from carbonaceous aerosols is difficult to estimate because, among other factors, it depends on the amount of absorption by the aerosols in the cloud. It is also highly sensitive to the assumed pre-existing, natural aerosol abundance. An upper limit for the cloudy-sky forcing by carbonaceous aerosols is $-4.4 \mathrm{Wm}^{-2}$, but may range as low as $-2.4 \mathrm{Wm}^{-2}$, depending on background aerosol concentrations. These estimates do not yet account for absorption of radiation by black carbon associated with cloud or the presence of pre-existing dust particles.
\end{abstract}

Keywords - Radiative forcing; Aerosols; Cloud droplet nucleation; Climate change

\section{INTRODUCTION}

Atmospheric aerosols along with greenhouse gases and clouds play important roles in mediating the radiation balance of the Earth-atmosphere system. In recent assessments of climate forcing, the Intergovernmental Panel on Climate Change (IPCC) lists aerosols as one of the most important anthropogenic radiative agents that tend to decrease temperature (IPCC, 1994). However, the magnitude of aerosol effects on climate and, in particular, the magnitude of the indirect effect of aerosols on clouds is still very uncertain (IPCC, 1994; Penner et al., 1994a). While a variety of aerosol types exist in the atmosphere (e.g., water-soluble inorganic species, carbonaceous aerosols (i.e. organic matter and black carbon aerosols), mineral dust, and sea salt), volatile sulfur compounds are particularly important aerosol precursors. This is because a large part of the aerosol mass in sub-micron size particles is sulfate. Sulfate aerosol is formed through chemical reactions, either gas phase photochemical reactions of the emitted sulfur compounds or aqueous processes involving in-cloud oxidation of $\mathrm{SO}_{2}$ followed by drop evaporation (Hoppel et al., 1990; Lelieveld and Heintzenberg, 1992). The second most important aerosol component in the sub-micron size range is organic.carbon. Our studies of the effect of aerosols on climate and climate forcing have initially concentrated on characterizing the effects of anthropogenic sulfate aerosols (Penner et al., 1994b; Taylor and Penner, 1994; Chuang and Penner, 1995; Chuang et al., 1995). Here we review these estimates of forcing and extend them to include an upper limit for the cloudy-sky forcing by carbonaceous aerosols.

In order to provide a global understanding of the effects of aerosols on clouds, one must first understand the global concentrations of the different aerosol components or types. Our past work has been aimed at developing an understanding of global and regional aerosol abundances, and developing a parameterization of cloud response to aerosol abundance (Chuang and Penner, 1995; Ghan et al., 1993) in order to evaluate the importance of aerosol/cloud interactions to climate forcing. The effect of aerosol abundance on cloud life cycle may also be important but is not treated here. In order to understand 
whether the aerosol particles act as a CCN, one needs to know the composition of hygroscopic material in the aerosol (e.g., sulfate, nitrates, ammonium) (Pruppacher and Klett, 1978). This understanding requires a quantitative understanding, on a global basis, of the aerosol sources, transformation and removal processes. Determining the aerosol sources requires an understanding of the cycles and budgets for the trace species which comprise the aerosol.

Carbonaceous aerosols derive from both anthropogenic and natural sources. They are composed of two components, called black carbon and organic carbon. Organic carbon, like sulfate aerosol is mainly scattering. Black carbon may be distinguished by its resistence to chemical and thermal attack and by its ability to strongly absorb solar radiation; specific absorption coefficients are estimated in the range of 3 to $20 \mathrm{~m}^{2} \mathrm{~g}$ (Liousse et al., 1993). This ability lowers the single scattering albedo of aerosols thereby reducing the amount of solar radiation reflected by the aerosols (Chylek and Coakley, 1974). It is important to quantify the amount of black carbon (as well as organic carbon and sulfate aerosol) in order to quantify climate forcing by anthropogenic aerosols. The presence of black carbon in cloud may also reduce cloud albedo. Here we ignore this effect and concentrate on obtaining an upper-limit estimate of the effect of carbonaceous aerosols on clouds and on showing the sensitivity of this forcing to preexisting aerosol number concentrations.

\section{SOURCES OF CARBONACEOUS AEROSOLS}

The principal source of black carbon is combustion. Except for natural fires, whose sources are small on a global basis, most black carbon derives from either biomass burning or fossil fuel combustion. The principal types of biomass burning include (1) savanna fires to clear and renew land, (2) forest fires for clearing purposes, (3) burning of agricultural waste to clear land, and (4) the burning of wood to produce charcoal and (5) the burning of wood, agricultural wastes, charcoal, and dung for domestic fuel. Each of these processes produce organic carbon as well, although the ratio of $\mathrm{BC}$ to $\mathrm{OC}$ in emissions varies depending on the type of fuel and the manner of burning. For example, savanna fires typically have a larger ratio of $\mathrm{BC} / \mathrm{OC}$ than forest fires. This is because savanna fires typically burn in a flaming mode which enhances emissions of $\mathrm{BC}$ while forest fires are a combination of flaming and smoldering.

The principal sources of black carbon from fossil fuel emissions derive from diesel fuel use and coal combustion (Penner et al., 1993; Cooke and Wilson, 1995). On a global basis these emissions have been estimated from fuel use statistics as $6.6 \mathrm{Tg} / \mathrm{yr}$ by Penner et al. (1993) and as $8.0 \mathrm{Tg} / \mathrm{yr}$ by Cooke and Wilson (1995). In the following estimates of forcing, the inventory of Penner et al. (1993) has been used.

Emissions of organic carbon from fossil fuels and other activities within an urban complex are not well known, but, typically, the concentration of OC is larger than that of $\mathrm{BC}$ in urban areas (Bremond et al., 1989; Rogge et al., 1993). The source of this OC is not necessarily associated with the main sources of BC in any given urban area (Gray et al., 1984). In the absence of good emissions inventories for $\mathrm{OC}$ from these sources, in the following we used an estimate for the ratio of $\mathrm{OC}$ to $\mathrm{BC}$ emissions from measured ratios of $\mathrm{OC}$ to $\mathrm{BC}$ in urban regions (which range up to $3.5 \mathrm{gC} / \mathrm{gC}$ ) to define the range of possible emissions of $\mathrm{OC}$ from fossil fuel burning and urban activities. The resulting total emissions must also account for the particular molecular form of the organic compounds measured as OC. Assuming a conversion factor of 1.3 gives an estimated upper limit for these emissions of approximately $30 \mathrm{Tg} / \mathrm{yr}$. We have distributed these emissions proportional to our emissions of $\mathrm{BC}$ from fossil fuels, but we stress here the uncertainty in this distribution as well as its magnitude. It is important to obtain a better understanding of these emissions and their distribution as a function of space and time in order to improve estimates of forcing by carbonaceous aerosols.

In order to estimate forcing by carbonaceous aerosols, we developed a detailed inventory of anthropogenic emissions from biomass burning. For this inventory we estimated the fraction of $\mathrm{BC}$ and OC emitted from each source type using measured values of emission factors from the literature. For this inventory, forest and savanna burning were taken from the work of Hao et al. (1990), but updated to account for new information on the frequency of burning and the carbon stocks available to burn in grasslands (Menaut et al., 1991). Agricultural burning was estimated from country by country totals for the production of rice, wheat, barley, oat, rye and course grains, corn, and sugar cane as derived from 
FAO (1991). The total burned took into account the fraction used for fuel ( $60 \%$ in developing countries; Middleton and Darley, 1973; Mahtab and Islam, 1984; Barnard and Kristofersen, 1985; Crutzen and Andreae, 1990) and the fraction burned in the field. For the latter calculation we estimated the total amount of agricultural waste associated with the amount of grain produced from the harvest index of each crop. The fraction of this waste submitted to fires and the combustion efficiency (or fraction of waste submitted to fires that actually burns) were estimated separately. Table 1 gives a summary of the factors which contribute to our calculations and emissions.

Table 1. Biomass fires : Coefficients used to obtain amount of burned biomass from crop and fuels.

\begin{tabular}{|c|c|c|c|c|c|}
\hline & $\begin{array}{l}\text { By Product }{ }^{1} / \\
\text { Main Product }\end{array}$ & $\begin{array}{c}\text { By Product } \\
\text { Exposed to } \\
\text { Fires (\%) }\end{array}$ & $\begin{array}{c}\text { Combustion } \\
\text { Efficiency (\%) }\end{array}$ & $\begin{array}{c}\text { Emission } \\
\text { Factor } \\
\mathrm{TP} \text { (g/ kg fuel) }\end{array}$ & $\begin{array}{c}\text { Emission } \\
\text { Factor } \\
\mathrm{BC} \text { (g/kg fuel) }\end{array}$ \\
\hline Savanna & & & & 8.1 & 0.81 \\
\hline Forest & & & & 18 & 1.53 \\
\hline Rice & & & & & \\
\hline Developed Areas & 1.2 & 10 & 85 & 2.5 & .6 \\
\hline Developing Areas & 1.2 & 50 & 85 & $5.3^{2}$ & $.864^{2}$ \\
\hline \multicolumn{6}{|l|}{$\begin{array}{l}\text { Wheat, Barley, } \\
\text { Rye and others }\end{array}$} \\
\hline Developed Areas & 1.3. & 5 & 70 & 7.0 & .91 \\
\hline Developing Areas & 1.3 & 30 & 70 & $12.0^{2}$ & $1.2^{2}$ \\
\hline \multicolumn{6}{|l|}{ Corn } \\
\hline Developed Areas & 1.0 & 5 & 35 & 5.0 & .7 \\
\hline Developing Areas & 1.85 & 30 & 35 & $12.0^{2}$ & $.96^{2}$ \\
\hline \multicolumn{6}{|l|}{ Sugar Cane } \\
\hline Developed Areas & 0.5 & 10 & 35 & 5.0 & .775 \\
\hline Developing Areas & 0.5 & 70 & 35 & $7.0^{2}$ & $.77^{2}$ \\
\hline \multicolumn{6}{|l|}{ Wood } \\
\hline Developed Areas & & 80 & 90 & 11 & 1.32 \\
\hline \multicolumn{6}{|l|}{ Developing Areas } \\
\hline Burned for fuel & & 50 & 90 & 11 & 1.2 \\
\hline Burned for & . & & & & \\
\hline charcoal making & & 50 & 20 & 17 & 0.85 \\
\hline \multicolumn{6}{|l|}{ Charcoal } \\
\hline Developed Areas & & 100 & 75 & 10 & 1.5 \\
\hline Developing Areas & & 100 & 75 & 10 & 1.5 \\
\hline Dung & & 18.5 & 50 & 20 & 1.0 \\
\hline
\end{tabular}

1 In the case of rice, wheat, rye, barley and corn, the main product is the grain and the by product (or waste), the straw. Sugar is considered to be the main product of the sugar cane crop.

2 These emission factors are higher because $60 \%$ of the burning is assumed to take place as domestic burning rather than in the field. There is consequently a higher fraction of smoldering with higher total particle emission factors but a lower fraction of BC/TP emissions.

In addition to forest, savanna, and agricultural burning (in both field and as domestic fuel), charcoal, waod, and dung are burned as fuels. The total amounts burned from these sources and the total emissions are shown in Table 2. There is a crucial lack of data concerning the proper parameters to use in these calculations. For example, the emission factors for charcoal making and burning of wood directly differ greatly. In our inventory, $50 \%$ of the fuel wood was estimated to be used for charcoal making in the developing countries and $50 \%$ for direct fuel use. This ratio could be improved based on recent evaluations (Brocard et al., 1995). 
To check the magnitude and distribution of the emissions described above, requires that we represent these aerosols in a three-dimensional model of transport, transformation and removal and use the predictions of the model in comparison to observations to quantify possible errors in both emissions and model representation. Black carbon concentrations are almost exclusively from combustion and of anthropogenic origin, while measured abundances of $\mathrm{OC}$ at any given site also result from natural sources. Therefore, a proper test of the model and the emissions of $O C$, requires that both sources be represented. Natural emissions of $\mathrm{OC}$ derive from the gas to particle conversion of natural organic vapors emitted by vegetation, direct particle emissions from vegetation and other debri of biological origin. Vegetation emits isoprene, terpenes, and a variety of oxygenated species. All of these compounds 
Table 2. Biomass Burning Sources : Total fuel burned in each category (savanna, forest, agricultural and domestic fires).

\begin{tabular}{|r|c|c|c|}
\hline & $\begin{array}{c}\text { Total Biomass } \\
\text { Burned (Tgdm/yr) }\end{array}$ & $\begin{array}{c}\text { TP Emissions } \\
\text { (Tg/yr) }\end{array}$ & $\begin{array}{c}\text { BC Emissions } \\
(\mathrm{Tg} / \mathrm{yr})\end{array}$ \\
\hline Total Savanna & $\mathbf{5 3 7 4 . 5}$ & $\mathbf{5 9 . 9}$ & $\mathbf{5 . 6 4}$ \\
\hline Forest & $\mathbf{2 6 8 2}$ & $\mathbf{2 1 . 7}$ & $\mathbf{2 . 2}$ \\
\hline Agricultural Fires & $\mathbf{1 2 5 9}$ & $\mathbf{2 2 . 7}$ & $\mathbf{1 . 9}$ \\
\hline Wheat and other grains & 192 & $\mathbf{5 6 4 5}$ & $\mathbf{0 . 5 3}$ \\
Corn & 41.1 & 2.06 & 0.22 \\
Rice & 218.5 & $\mathbf{0 . 4 6}$ & 0.04 \\
Sugar Cane & 112.4 & 1.15 & 0.19 \\
\hline Domestic Fires & $\mathbf{8 6 9 . 5}$ & 0.78 & 0.09 \\
Wood and Bagasse & 752.4 & $\mathbf{1 1 . 0 7}$ & $\mathbf{1 . 0 1}$ \\
Charcoal & 16 & 8.88 & 0.88 \\
Dung & 101.1 & 0.16 & 0.02 \\
\hline
\end{tabular}

undergo photochemical degradation in the atmosphere, but terpenes are thought to have the largest particle yields. The fraction of organic matter produced from a given amount of terpene emissions varies over a considerable range, but a gas to particle conversion factor of $5 \%$ represents a reasonable average (Pandis, et al., 1991; Hatakeyama et al., 1991; Zhang et al., 1992). This factor, together with the terpene emission inventory of Guenther et al. (1995) gives rise to a total natural organic matter production of 7.8 $\mathrm{Tg} / \mathrm{yr}$. Because the time scale for oxidation of the terpenes is short (of the order of minutes), we assume that this source is directly injected into the model as aerosol. The latter two natural sources, those from direct injection of plant materials and biological debri, are particularly difficult to estimate. However, most of the mass of these emissions are in the coarse particle mode, above $1 \mu \mathrm{m}$ diameter. Hence, their contribution to measured concentrations $<2.5 \mu \mathrm{m}$ should not be large. In the following simulations, these emissions have been neglected.

\section{COMPARISON TO DATA}

There are very few data which can be used to verify the model, and much of it consists of short duration measurements. which are therefore insufficient for defining a climatology of carbonaceous aerosols (especially a climatology of organic carbon aerosols). Liousse, et al. (1995) have carried out a thorough comparison of the model with those measurements which are available, concluding that the model provides a reasonable description of both $\mathrm{OC}$ and $\mathrm{BC}$ concentrations. Figure 1ab shows a scatter plot of observed and model predicted concentrations of $B C$ and $\mathrm{OC}$. The figure demonstrates that the emissions and model are not biased either high or low, although, if we look in more detail, particularly in the United States, for example, concentrations of both BC and OC appear to be low (Liousse, et al., 1995). This is most likely the result of the emission inventory being too low in the United States rather than due to weaknesses in the model.

One weakness of the model is apparent when comparing modeled and predicted concentrations at polar locales. The predicted concentrations at both the North and South Poles appear to be too low. Low concentrations at remote locales may result from either (1) low emissions inventory, (2) a scavenging parameterization which removes too much material, or (3) a poor representation of atmospheric circulation and transport. The representation of scavenging may be evaluated by comparison of predicted and observed concentrations in precipitation (see Liousse et al., 1995) or by comparison of observations and model results at remote sites, where predicted concentrations are highly sensitive to the scavenging parameterization. Figure 2 compares the model and predicted concentrations of BC at Mauna Loa, a site mainly impacted by emissions in Asia. As seen there, the predicted concentrations are reproduced to within a factor of two. One complicating factor in comparing these data is the fact that $\mathrm{BC}$ as measured by an aethelometer may count some absorption by dust, attributing this to black carbon. Schnell et al. (1994) presented evidence that dust absorption could account for up to $20 \%$ of the BC measured at Mauna Loa during special Asian dust events (mean value of $10 \%$ ). Our predicted concentrations are 
therefore within a factor of two of those measured which we deem adequate for this first estimate. This fact, together with our reasonable reproduction of concentrations in rain (Liousse et al., 1995) gives us confidence in our scavenging scheme. South Polar concentrations are affected mainly by biomass burning in the Southern Hemisphere. The magnitude of these sources is best checked by comparison of the predicted concentrations with sites close to the burning. One such comparison, for Amsterdam Island, gave good agreement, thereby confirming that our sources from Africa are reasonable (Liousse et al., 1995). The seasonal cycle of carbon monoxide is also mainly dependent on the sources from biomass burning in the Southern Hemisphere and is a gas whose sink does not depend on the scavenging parameterization in the model. A comparison of this model's predicted CO fields (see Atherton et al., 1995) with data from Cape Grim (not shown) gives us further confidence that the specified emissions from biomass burning are reasonable. Hence, we conclude that the low concentrations predicted at the South Pole are mainly due to a poor representation of the circulation in this region. A similar weakness may affect the model's ability to represent concentrations in North Polar regions. This weakness should not greatly affect the predicted forcing by carbonaceous aerosols, because such a small region is affected. However, we hope to correct this in the future.
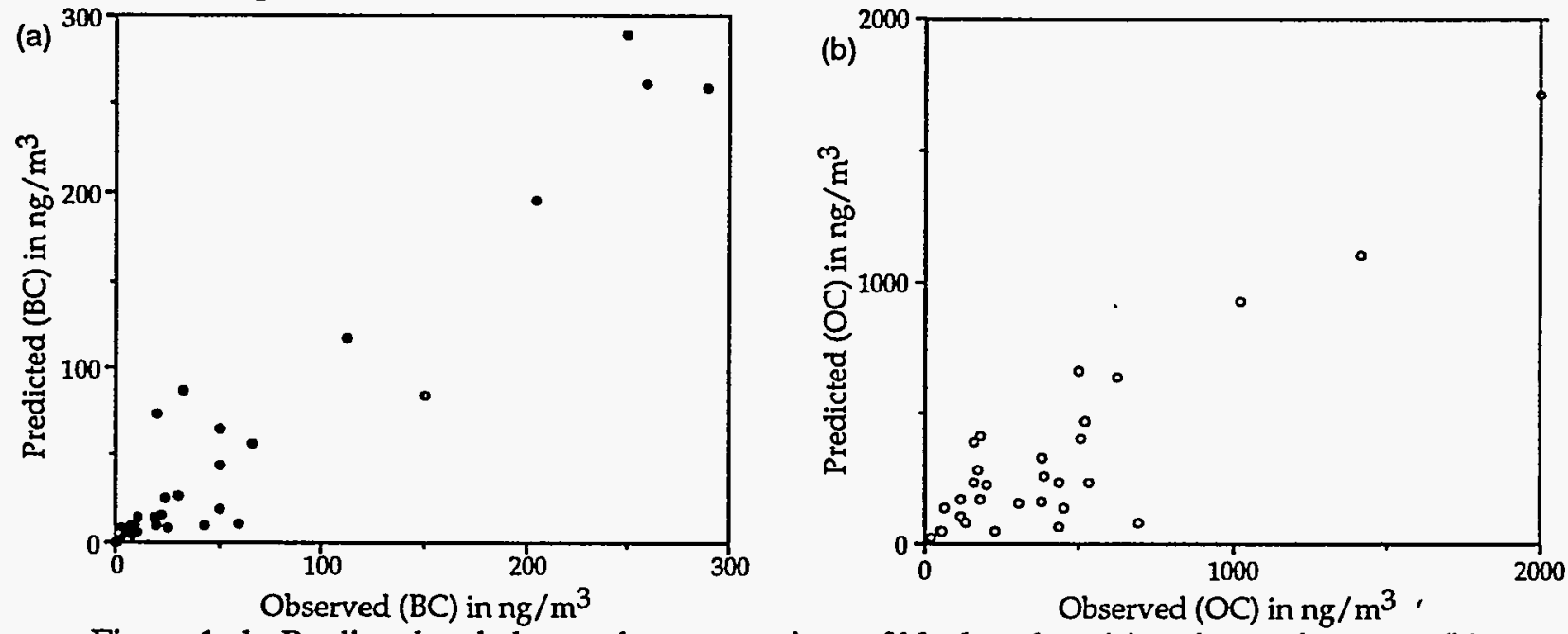

Figure 1 ab: Predicted and observed concentrations of black carbon (a) and organic matter (b).

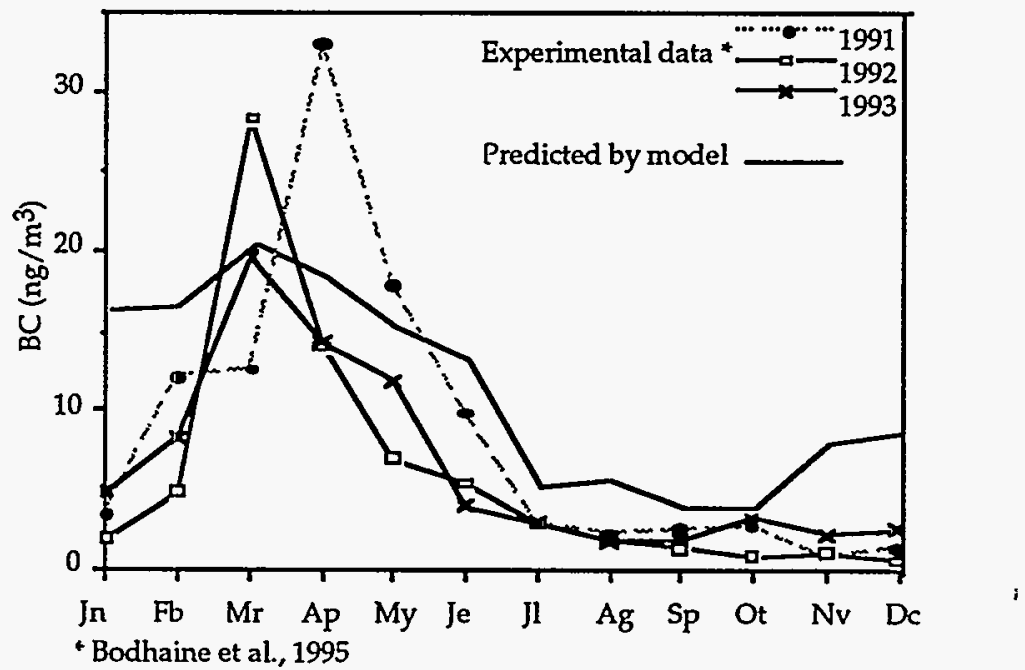

Figure 2: Predicted and observed concentrations of black carbon at Mauna Loa. 
THE EFFECTS OF AEROSOLS ON CLOUDS

Recently, Boucher and Rodhe (1994) and Jones et al. (1994) have each developed parameterizations relating cloud drop concentration to sulfate mass or aerosol number concentration, respectively, and used them to develop estimates of the indirect forcing by anthropogenic sulfate aerosols. These parameterizations made use of measured relationships in continental and maritime clouds. However, these relationships are inherently noisy, yielding more than a factor of 2 variation in cloud drop number concentration for a given aerosol number ( or for a given sulfate mass) concentration. They do not make use of information from the climate model regarding local updraft velocities, and they have had to make certain simplifying assumptions.

In the study by Boucher and Rodhe (1994), simultaneous aerosol mass and CCN number concentration measurements were used to establish a hypothetical range of dependencies between the sulfate aerosol mass and cloud drop number concentration. However, their results of the indirect radiative forcing by sulfate aerosols are sensitive to these assumed relationships and the predicted forcing may be overestimated when comparing with observations of cloud drop radius and cloud albedo. In the study by Jones et al. (1994), aerosol number concentration was related to cloud drop number concentration based on measurements. But in converting the model-predicted sulfate mass concentrations to aerosol number concentrations for use in the parameterization, the aerosol composition and size distribution were prescribed and assumed to be universally applicable both in the case of the natural background aerosol (present prior to industrialization) and in the present-day perturbed case.

In contrast to previous studies, our parameterization of the effects of aerosols on cloud droplet distributions uses a more mechanistic approach. The characteristics of the cloud drop size distribution near cloud base are initially determined by the size distribution and chemical characteristics of the aerosol particles that serve as CCN and by the local updraft velocity (Lee et al., 1980; Chuang et al., 1992). Once drop concentrations at cloud base are established, measurements have shown that these remain near constant with altitude throughout the main part of the clouds, at least in the case of stratiform and stratocumulus clouds (Nicholls, 1984; Bower et al., 1994; Mitchell, DRI, private communication). Thus, ideally, it should be possible to use these fundamental properties of aerosol size, chemical composition, and updraft at cloud base to predict the effects of anthropogenic aerosols on drop number concentrations in stratiform clouds in general circulation models. However, the large spatial and temporal variability in the concentration, chemical characteristics, and size distribution of aerosols have made it difficult to develop such a parameterization from data.

In our parameterization, our focus has been to develop a means for relating the predicted anthropogenic sulfate mass to cloud drop number concentration over the range of expected conditions associated with continental and marine aerosols. We start with an assumed pre-existing particle size distribution and develop an approximation of the altered distribution after addition of anthropogenic sulfate. This treatment is necessary for sulfate aerosols because the time scale for production from gas phase $\mathrm{SO}_{2}$ is several days. Other aerosol types, such as the carbonaceous particles of concern here, are formed much more quickly from their gas phase precursors and hence may be assumed to be injected into a global-scale model in the aerosol form. In the calculation of sulfate aerosol, we assume that sulfate is formed mainly through the condensation of sulfuric acid vapor $\left(\mathrm{H}_{2} \mathrm{SO}_{4}\right)$ on pre-existing particles and aqueous-phase oxidation of $\mathrm{SO}_{2}$ followed by evaporation of the drops. The nucleation of new particles is neglected. We thereby develop a conservative estimate of the possible change in CCN number concentration due to anthropogenic sulfate-containing aerosols and investigate its impact on cloud albedo and global average solar radiative forcing.

As noted above, the assumed pre-existing particle size distribution derives from a variety of sources, including the gas-to-particle conversion of natural emissions of non-methane hydrocarbons (primarily terpenes), natural water-soluble inorganic species (sulfates, nitrates, ammonium), dust, and sea salt. The sources of these aerosols are regionally diverse. We are working towards the development of global scale distributions for each of these aerosol types. At the present time, we are able to represent the most important sub-micron components which comprise the main mass of sub-micron aerosol, namely organic, black carbon, and sulfate aerosols (Liousse et al., 1995; Penner et al., 1994b). However, the pre- 
existing aerosol should also include a representation of particles whose mass is mainly in the course mode as well.

In Chuang et al. (1995) and here, we assume the sulfate-containing aerosol is an internal mixture, where a fraction of the aerosol size distribution is determined by condensation of sulfuric acid vapor on a prescribed pre-existing particle distribution and a fraction was determined by aqueous-phase oxidation of $\mathrm{SO}_{2}$ followed by evaporation of the drops. Based on Langner and Rhode (1991), as well as our own model simulations (Penner et al., 1994c), we explored a range of conditions for the gas and aqueous production pathways. Thus, it was assumed that 15 to $35 \%$ of aerosol sulfate is distributed to all particles by condensation and the remaining 85 to $65 \%$ to particles which were larger than the minimum size of CCN by cloud processes. Here, we use the mid-range figure of $75 \%$ to calculated the cloud forcing by anthropogenic sulfate aerosol. This internal mixing approach does not change the total aerosol number, but the resulting sulfate-containing particles grow to larger sizes and thereby form more $\mathrm{CCN}$.

\section{CLOUD DROP NUCLEATION}

An aerosol particle becomes activated as a CCN when the environmental supersaturation ratio becomes greater than its critical value. The resulting drop grows to a size much larger than the initial size of the particle due to condensation of water. The magnitude of the critical supersaturation for activation decreases with increasing particle size and mass fraction of soluble material in the aerosol particle; therefore, larger particles are activated earlier than smaller particles and activation of maritime aerosols whose composition contains a large fraction of soluble salts (Heintzenberg, 1989) is more favorable than continental particles for a given value of supersaturation. Here, we describe our parameterization to relate anthropogenic sulfate-containing aerosols to cloud drop nucleation.

The detailed microphysical model described by Chuang et al. (1992) was used to compute the spectral evolution of interstitial aerosols and cloud drops. This model describes a Lagrangian air parcel which may also entrain environmental air. The model is initialized with the aerosol size distribution and chemical composition determined as noted above and computes the concentration of cloud droplets formed as the parcel passes through cloud base. In Chuang et al. (1995) and Chuang and Penner (1995), we assumed the parcel dynamics were adiabatic because we were interested only in the initial stages of cloud development. The vertical temperature and humidity profiles were those used by Lee et al. (1980). We examined the consequence of water vapor diffusion to aerosols which were an internal mixture of sulfate and other materials (organic matter, $\mathrm{NO}_{3}{ }^{-}, \mathrm{NH}_{4}{ }^{+}$, etc.).

Figures $3 \mathrm{a}$ and $3 \mathrm{~b}$ present the predicted relationship between anthropogenic sulfate in particles and cloud drop number concentration as predicted by our microphysical model. In these figures, we varied the aerosol number concentration from $500-10000 \mathrm{~cm}^{-3}$ for the continental case (Fig. 3a) and from 50 $500 \mathrm{~cm}^{-3}$ for the marine case (Fig. $3 b$ ) to cover the spatial and temporal variations expected for the concentrations of pre-existing aerosols. In addition, we also considered updraft velocities ranging from $10 \mathrm{~cm} \mathrm{~s}^{-1}$ to $200 \mathrm{~cm} \mathrm{~s}^{-1}$ to cover a wide range of updrafts expected in both stratus and stratocumulus clouds. Looking at any one curve in Fig. 3, one notes that under many circumstances the predicted cloud drop number concentration is larger on particle size distributions with a higher loading of anthropogenic sulfate even though, for this internally mixed case, the total number of aerosol particles is unchanged in these simulations. The concentration of cloud drops is, of course, also affected by both updraft velocity and total (in this case pre-existing) aerosol number. For the continental case with a moderate updraft velocity $50 \mathrm{~cm} \mathrm{~s}^{-1}$ and aerosol number $2000 \mathrm{~cm}^{-3}$, we estimate that the number of the condensationallyproduced cloud drops would increase from 350 to $560 \mathrm{~cm}^{-3}$ if a typical amount of anthropogenic sulfate of $\sim 2 \mu \mathrm{g} \mathrm{m}^{-3}$ in non-urban regions were added onto the pre-existing particles. For the marine case with the same updraft velocity but a much lower aerosol concentration of only $100 \mathrm{~cm}^{-3}$, the number of cloud drops nucleated would increase from 60 to $75 \mathrm{~cm}^{-3}$ for a total deposition of anthropogenic sulfate equal to $0.2 \mu \mathrm{g} \mathrm{m}^{-3}$.

It is important to try to compare these results with available data. We have compared our model results with measurements of the relationship between drop number concentration and sulfate concentration in cloud water samples (Leaitch et al., 1992). Leaitch et al. report measurements conducted over central Ontario, Canada and over upper New York State. The observed ranges of cloud drop number concentrations are about $55-750 \mathrm{~cm}^{-3}$ for stratiform clouds and $160-950 \mathrm{~cm}^{-3}$ for cumuliform clouds (derived from Eqs. (1) and (2) of Leaitch et al., 1992) for cloudwater sulfate concentrations ranging from 0.05 to $10 \mu \mathrm{g} \mathrm{m}^{-3}$. For the same range of sulfate concentrations (presumably 
anthropogenic), our simulations show that the number concentrations of cloud drops which are nucleated on continental aerosol size distributions with total number concentrations $500-10000 \mathrm{~cm}^{-3}$ are about 50 $910 \mathrm{~cm}^{-3}$ for updraft velocities $10-50 \mathrm{~cm} \mathrm{~s}^{-1}$. The predicted cloud drop numbers through nucleation on anthropogenic sulfate-containing aerosols seem to be in the right range.
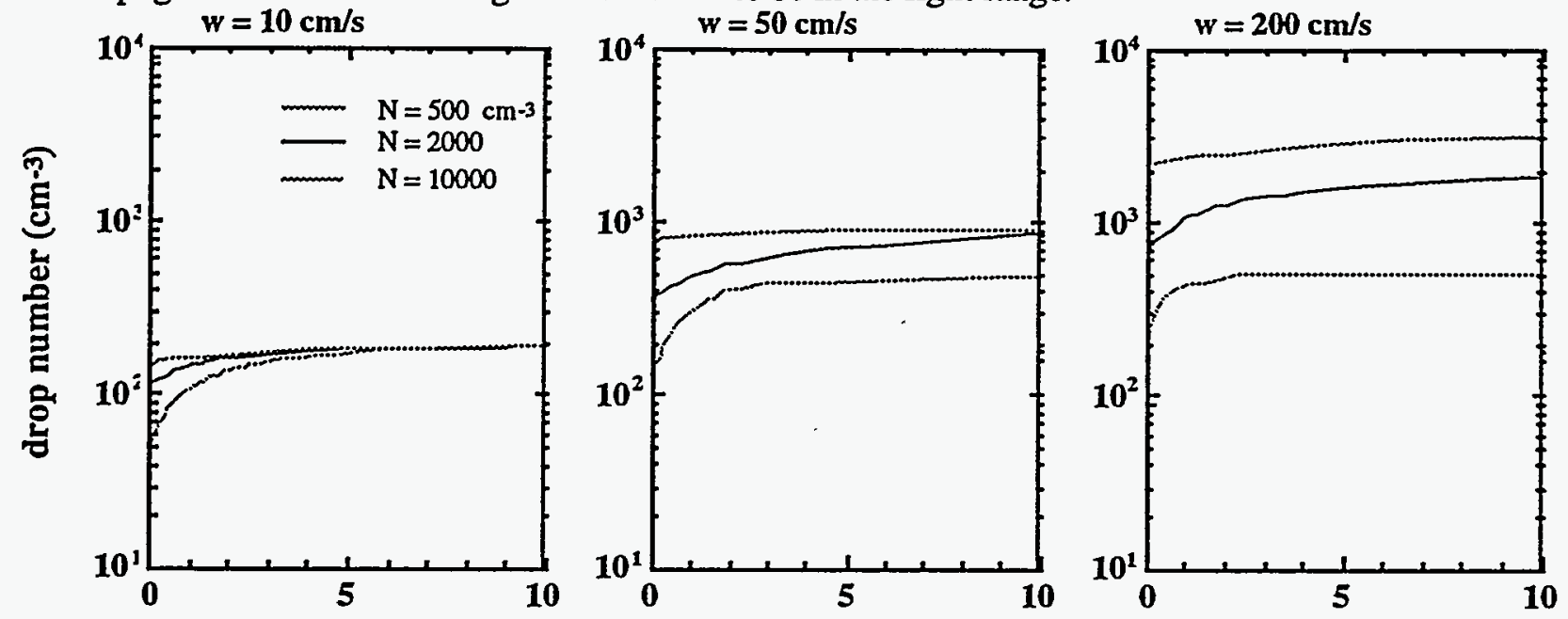

anthropogenic sulfate $\left(\mu \mathrm{g} \mathrm{m}^{3}\right)$

Figure 3a: Predicted cloud drop number nucleated versus anthropogenic sulfate in continental particles. Aerosol number concentrations are from $500-10000 \mathrm{~cm}^{-3}$.
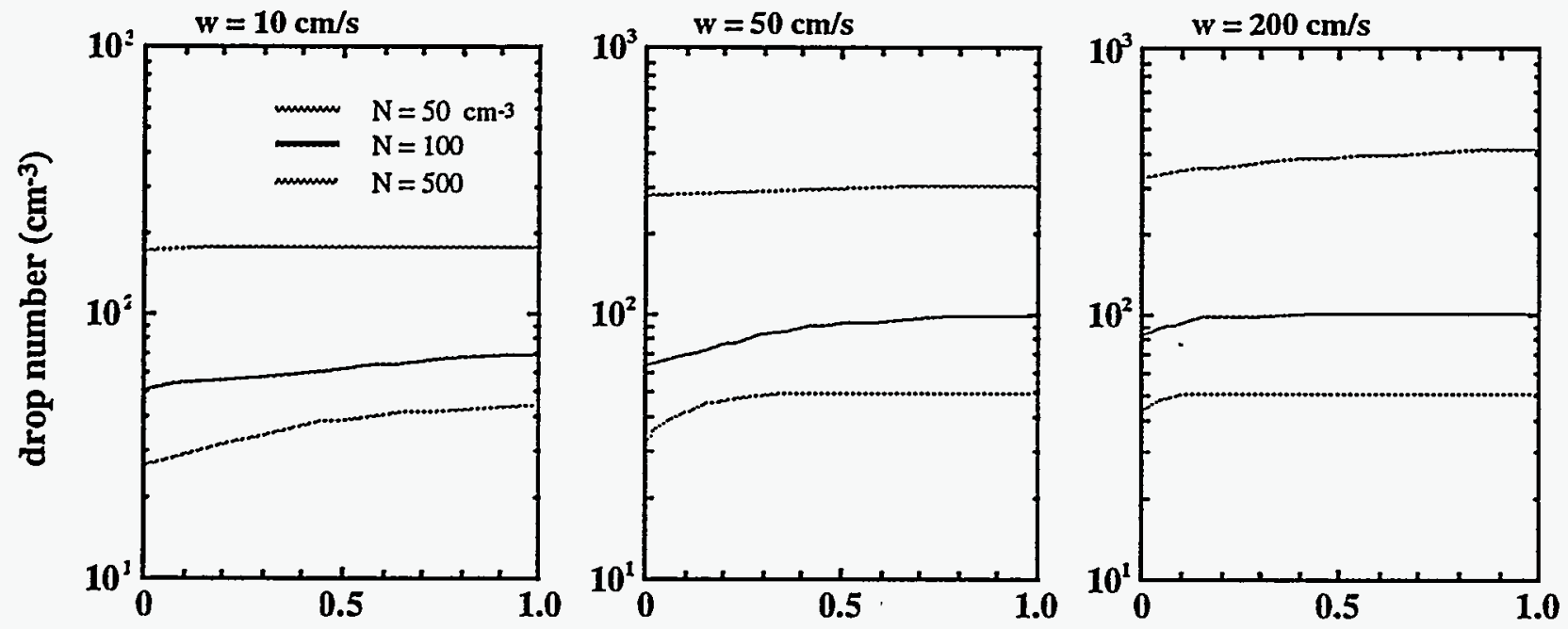

anthropogenic sulfate $\left(\mu \mathrm{g} \mathrm{m}^{-3}\right)$

Figure 3b. Same as Fig. 3a but for marine aerosols with number concentrations from $50-500 \mathrm{~cm}^{-3}$.

PARAMETERIZATION AND FORCING IN A GLOBAL MODEL

The effect of anthropogenic sulfate accumulation on pre-existing aerosols has a significant influence on cloud drop number concentration; therefore, it should be represented in climate models. However, it is not practical to apply a detailed microphysical model in a global climate model because of the large increase in computational time required for the detailed treatment of nucleation at each grid point. An alternative is to parameterize the cloud drop nucleation and then apply this parameterization in climate models. Here, we parameterize the nucleation of cloud drops onto anthropogenic sulfatecontaining aerosols based on the results from our detailed microphysical model. The cloud drop number nucleated (in $\left.\mathrm{cm}^{-3}\right)$ is expressed in the form $N_{\mathrm{d}}=w N_{\mathrm{a}} /\left(w+c N_{\mathrm{a}}\right)$ as suggested by Ghan et al. (1993), where $N_{\mathrm{a}}\left(\mathrm{cm}^{-3}\right)$ is the background aerosol number concentration, and $w$ is the updraft velocity in $\mathrm{cm} \mathrm{s}^{-1}$. In Ghan et al., a look-up table was used for scaling the value of $c$ such that the parameterized drop 
concentrations match the simulated values from our detailed microphysical model (Chuang et al., 1992; Edwards and Penner, 1988). In Chuang and Penner (1995) and Chuang et al. (1995), we derive the coefficient $c$ directly from the results of our microphysical model. 
Table 3. Global average annual mean change in cloud forcing $\left(\mathrm{Wm}^{-2}\right)$.

\begin{tabular}{|l|l|c|c|}
\hline & \multicolumn{1}{|c|}{$\begin{array}{c}\text { Assumed pre- } \\
\text { existing aerosol }\end{array}$} & Forcing $\left(\mathrm{Wm}^{-2}\right)$ & $\begin{array}{c}\text { Forcing with } \\
\text { prescribed pre- } \\
\text { existing marine } \\
\text { source }\left(\mathrm{Wm}^{-2}\right)\end{array}$ \\
\hline $\begin{array}{l}\text { Anthropogenic } \\
\text { sulfate }\end{array}$ & $\begin{array}{l}\text { Anthropogenic OC } \\
\text { and BC, Natural } \\
\text { OC, BC, S }\end{array}$ & -0.87 & -0.57 \\
\hline $\begin{array}{l}\text { Anthropogenic } \\
\text { carbonaceous } \\
\text { aerosol }\end{array}$ & Natural OC, BC, S & -4.41 & -2.43 \\
\hline $\begin{array}{l}\text { Anthropogenic } \\
\text { sulfate and } \\
\text { anthropogenic } \\
\text { carbonaceous } \\
\text { aerosol }\end{array}$ & Natural OC, BC, S & -5.29 & \\
\hline
\end{tabular}

Results from this parameterization for sulfate cloud forcing using all carbonaceous aerosols as pre-existing aerosols are shown in Table 3 . The total forcing noted there is $\approx-0.9 \mathrm{Wm}^{-2}$. This table shows the predicted forcing from the model which assumes internal mixing and an assumed conversion fraction of $75 \%$ from aqueous reactions. We also show the predicted forcing for a calculation in which the preexisting aerosol is assumed to be only that from natural sulfur and natural organic matter aerosol. Here, the size distribution is that of the pre-existing aerosols from Chuang et al. (1995) and the anthropogenic carbonaceous aerosols have been added as an external mixture. The calculated forcing increases to $5.5 \mathrm{Wm}^{-2}$ with approximately $-4.4 \mathrm{Wm}^{-2}$ due to carbonaceous aerosols alone. Such forcing should be. interpreted as a maximum since we have assumed that any effect of black carbon on cloud drop reflectivity is negligible. In addition, we have not yet accounted for the "pre-existing" aerosol component that arises from sea salt or dust. In order to explore the possible effects of the latter, we performed a sensitivity test with a prescribed background of aerosol over marine areas. In this test, a prescribed particle number concentration of $200 \mathrm{~cm}^{-3}$ was added to the lowest marine boundary layer, and exponentially decreased with altitude by

$$
\begin{aligned}
\mathrm{N}\left(\mathrm{cm}^{-3}\right) & =200 \mathrm{e}^{-2(1-\sigma) .} & & \text { for } \sigma \geq 0.15 \\
& =36.5 \mathrm{e}^{-15(.15-\sigma)} & & \text { for } \sigma<0.15
\end{aligned}
$$

where $\sigma=p / p_{\mathrm{S}}$, and $p_{\mathrm{S}}$ is the surface pressure. These particles simulate a possible source of marine background particles such as sea salt or marine sources of organic aerosol. The global average annual mean radiative forcing is listed in Table 3 . The cloud forcing by carbonaceous aerosols decreased from $4.4 \mathrm{Wm}^{-2}$ to $-2.4 \mathrm{Wm}^{-2}$. Figure 4 shows the temporal distribution of this forcing, with largest forcing in April and September associated with tropical biomass burning of savanna and forested areas.

\section{CONCLUSIONS}

Greenhouse forcing has been estimated to be about $2.5 \mathrm{Wm}^{-2}$ over the last 100 years. Calculations shown here demonstrate that cloud forcing that results from anthropogenic emissions of carbonaceous aerosols may substantially mask the forcing by greenhouse gases. Further work is needed to appropriately estimate the pre-existing aerosol in order to better quantify this forcing. In addition, inclusion of the effect of black carbon on the single scattering albedo of clouds is needed. 


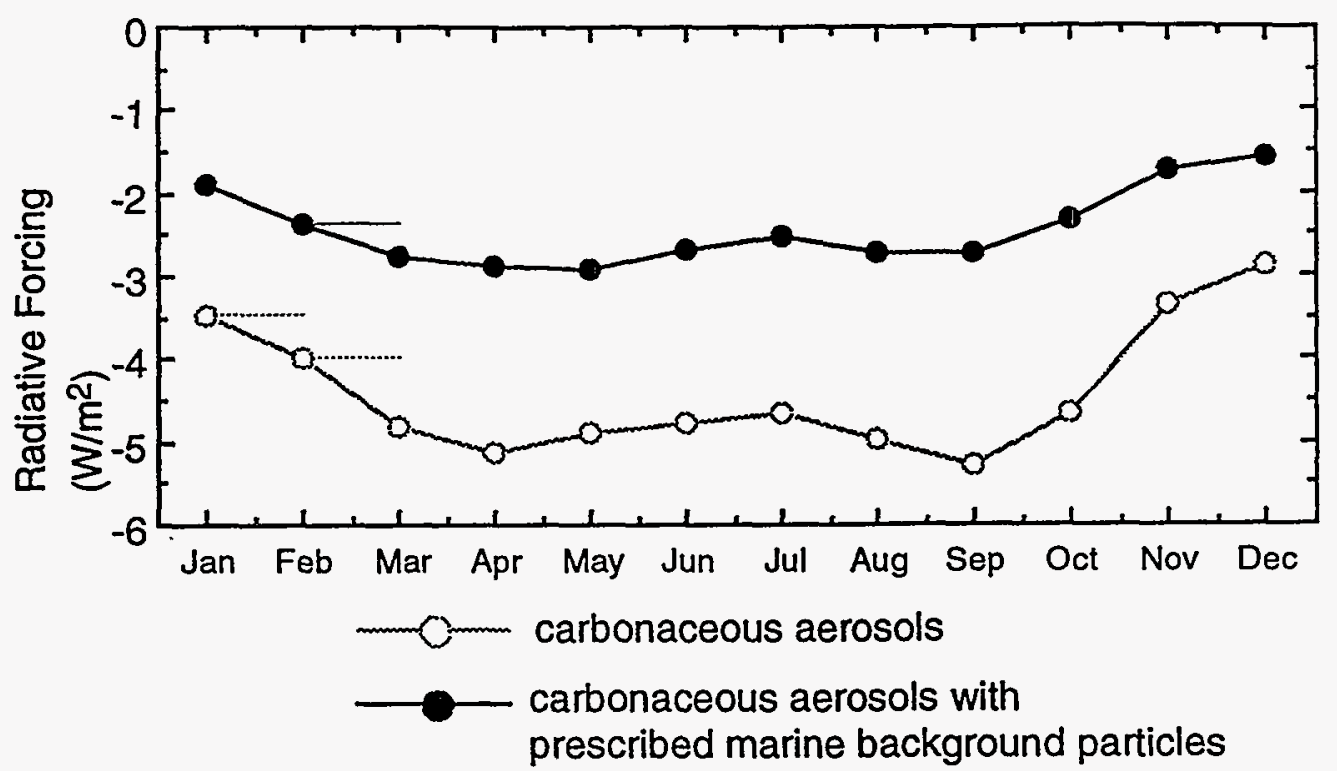

Figure 4. Cloud forcing from anthropogenic carbonaceous aerosols.

\section{ACKNOWLEDGMENTS}

This work was performed under the auspices of the U.S. Department of Energy under Contract W7405-Eng-48. Support from the NASA Aerosol Program and the DOE ARM Program is gratefully acknowledged.

\section{REFERENCES}

Atherton, C.A., J.E. Penner, J.J. Walton, D.D. Parrish (1996) Atmos. Envirron., in press.

Barnard, G., and L. Kristoferson (1985) Technical Report No 4, Earthscan, 178pp.

Bodhaine, B.A. (1995) J. of Geophys. Res., 100, 8967-8975.

Boucher, O. and H. Rodhe (1994) Report CM-83, Department of Meteorology, Stockholm University, 20pp.

Boucher, O. and U. Lohmann(1995) Tellus, 47B, 281-300.

Bower, K. N., Choularton, T. W., Latham, J., Baker, M. B., Jensen, J. and Nelson, J. (1994) J. Atmos. Sci., 51, 2722-2732.

Brémond, M.P., H. Cachier, and P. Buat-Ménard (1989) Env. Techn. Lett., 10, 339-346.

Brocard, D., C. Lacaux, J.P. Lacaux, G. Kouadio, V. Yoboué, M. Assa Achy, B. Ahoua and M. Koffi, (1995) Paper presented at the Chapman Conference, Biomass Burning and Global Change, Williamsburg, March 13-17, 1995.

Chuang, C.C., J.E. Penner, and L.L. Edwards (1992) J. Atmos. Sci., 49, 1264-1275.

Chuang, C.C., J.E. Penner, K.E. Taylor, and J.J. Walton (1994) in Conference on Atmospheric Chemistry, January 23-28, 1994, Nashville, TN, 170-174.

Chuang, C.C., and J.E. Penner (1995) Tellus, 47B, 566-577.

Chuang, C.C., J.E. Penner, K.E. Taylor, A.S. Grossman, and J.J. Walton (1995) J. Geophys. Res., in press.

Cooke, W.F., and J.J.N. Wilson (1995) J. of Geophys. Res., in press.

Chylek, P. and J.A. Coakley (1974) Science, 183, 75-77.

Crutzen, P.J. and M.O. Andreae (1990) Science 250, 1669-1678.

Edwards, L.L. and J.E. Penner (1988) in Aerosols and Climate, Edited by P.V. Hobbs and M.P. McCormick, pp. 423-434, A. Deepak Publishing, Hampton, VA.

Food and Agriculture, FAO Production Yearbook, vol. 45, $265 \mathrm{pp}, 1991$.

Ghan, S.J., C.C. Chuang, and J.E. Penner (1993) Atmos. Research, 30, 197-221. 
Gray, H.A., G.R. Cass, J.J. Huntzicker, E.K. Heyerdahl and J.A. Rau (1984) Sci. Total Environ., 36, 17-25.

Guenther, A., C.N. Hewitt, D. Erickson, R. Fall, C. Geron, T. Graedel, P. Harley, L. Klinger, M. Lerdau, W.A. McKay, T. Pierce, B. Scholes, R. Steinbrecher, R. Tallamraju, J. Taylor, and P. Zimmerman (1995) J. Geophys. Res., 100, 8873-8892.

Hao, W.M., M.H. Liu and P.J. Crutzen (1990) in Fire in the Tropical Biota, J.C. Goldammer ed., 440462.

Hatakeyama, S., K. Izumi, T. Fukuyama, H. Akimoto, and N. Washida (1991) J. Geophys Res., 96, 947-958.

Heintzenberg, J. (1989) Tellus, 41B, 149-160.

Hoppel, W. A., Fitzgerald, J. W., Frick, G. M., Larson, R. E. and Mack, E. J. (1990) J. Geophys. Res. 95, 3659-3686.

IPCC, Intergovernmental Panel on Climate Change (1994) Radiative Forcing of Climate 1994, Report to IPCC from the Scientific Assessment Working Group (WGI).

Jones, A., D. L. Roberts and A. Slingo (1994) Nature, 370, 450-453.

Langner, J. and H. Rodhe (1991) J. Atmos. Chem., 13, 225-263.

Leaitch, W. R., Isaac, G. A., Strapp, J. W., Banic, C. M. and Wiebe, H. A. (1992) J. Geopliys. Res., 97, 2463-2474.

Lee, I. Y., Hannel, G. and Pruppacher, H. R. (1980) J. Atmos. Sci. 37, 1839-1853.

Lelieveld, J., and J. Heintzenberg (1992) Science, 258, 117-120.

Liousse, C., H. Cachier and S.J. Jennings (1993) Atmos. Env., 27A, 1203-1211.

Liousse, C., J.E. Penner, C. Chuang, J.J. Walton, H. Eddleman, and H. Cachier (1995) J. Geophys. Res., in press.

Mahtab, F.U, and M.N. Islam (1984) Paper presented for Bangladesh Energy Planning Project Rural Energy Course Government of Bangladesh, Dhaka.

Menaut, J.C., L. Abbadie, F. Lavenu, P. Loudjani and A. Podaire (1991) in Global Biomass Burning J. S. Levine ed., MIT Press, 133-142.

Middleton, J.T., and E.F. Darley (1973) in Pollution : Engineering and Scientific Solutions, E.S. Barrekette, ed., Plenum, pp. 148-157.

Nicholls, S. (1984) Q. J. R. Met. Soc. 110, 783-820.

Pandis, S.N., S.E. Paulson, J.H. Seinfeld and R.C. Flagan (1991) Atmos. Env., 25A, 997-1008.

Penner, J.E., H. Eddleman and T. Novakov (1993) Atmos. Env., 27A, 1277-1295.

Penner, J.E., R.J. Charlson, J.M. Hales, N. Laulainen, R. Leifer, T. Novakov, J. Ogren, L.F. Radke, S.E. Schwartz, and L. Travis (1994a) Bulletin of the American Meteorological Society, 75, 375-400.

Penner, J.E.(1994b) in Changes in Land Use and Land Cover: A Global Perspective, edited by W.B. Meyer and B.L. Turner II, Cambridge University Press, 175-209.

Penner, J.E., C.A. Atherton, and T. Graedel (1994c) in Global Atmospheric-Biospheric Chemistry, ed. R. Prinn, Plenum Publishing, N.Y., 223-248.

Pruppacher, H.R. and J.D. Klett (1978) Microphysics of Clouds and Precipitation, D. Reidel Publ. Co., Boston, $714 \mathrm{pp}$.

Rogge, W.F., M.A. Mazurek, L.M. Hildemann, G.R. Cass, and B.R.T. Simoneit, B.R.T. (1993) Atmos. Environ. 27A, 1309-1330.

Schnell, R.C., D.T. Kuniyuki, B.A. Bodhaine and A.D.A. Hansen (1994) Paper presented at the Fifth Conference on Carbonaceous Particles in the Atmosphere, Berkeley, August 23-26, 1994.

Taylor, K.E., and J.E. Penner (1994) Nature, 369, 734-737.

Zhang, S.H., M. Shaw, J.H. Seinfeld, R.C. Flagan (1992) J. Geophys. Res., 97, 20717-20729. 